\title{
Educação ambiental corporativa para crianças: analisando a animação Peixonauta do Discovery Kids
}

\author{
Maria Lúcia Castagna Wortmann* \\ Daniela Ripoll $^{* *}$ \\ Laís Possamai ${ }^{* * *}$
}

\section{Resumo}

A partir da análise da série Peixonauta, desenho animado que integra a programação do canal de TV por assinatura Discovery Kids, vinculado ao grupo Discovery Channel, buscamos destacar como algumas problemáticas ambientais sáo apresentadas às crianças, bem como discutir como são delineadas, nesta série, algumas identidades preservacionistas. A animação Peixonauta dá destaque a questôes ambientais: introdução de espécies exóticas e domésticas na natureza, e o modo como essa prática afeta o meio ambiente; poluição das águas, solo e ar; e certos fenômenos naturais. Realizado na intersecção da Educação, da Educação Ambiental, dos Estudos Culturais e dos Estudos de Mídia, este estudo problematiza o modo como este desenho ensina quais açóes e quais problemas devem ser considerados relativamente aos chamados ambientes naturais. O corpus analítico compóe-se de 30 episódios que evidenciam quatro temáticas ambientais: a) reciclagem de materiais; b) introdução de espécies exóticas; c) poluição; d) mudanças climáticas e problemas associados. Os resultados sugerem que o Discovery Kids pratica uma espécie de "Educação Ambiental corporativa" ao introduzir e valer-se de temas "verdes" em sua programação. Em

\footnotetext{
Doutora em Educação pela Universidade Federal do Rio Grande do Sul (UFRGS). Professora da Universidade Luterana do Brasil (ULBRA) e Professora pesquisadora convidada da Universidade Federal do Rio Grande do Sul.

** Doutora em Educação pela Universidade Federal do Rio Grande do Sul (UFRGS). Professora do Programa de Pós-Graduação em Educação da Universidade Luterana do Brasil (ULBRA).

${ }^{* * *}$ Graduanda em Ciências Biológicas pela Universidade Luterana do Brasil (ULBRA). Bolsista PIBIC/CNPq - Projeto Pedagogia e produçôes da cultura: as programaçóes infantis do Discovery Kids.
} 
Peixonauta, tal intenção fica evidenciada. Algumas personagens representam sujeitos a serem conscientizados ambientalmente; outros ensinam o que é ser "ambientalmente responsável”. Há, também, os que detêm conhecimentos legitimados. Além disso, a tecnologia é colocada em destaque como meio seguro e rápido para a solução dos problemas ambientais. Mas, ao mesmo tempo, ao simplificar o encontro de soluçóes, a série operaria na direção da naturalização/banalização dos problemas ambientais, provocando o seu apagamento.

Palavras-chave: Educação Ambiental. Educação Ambiental Corporativa. Mídia Educação infantil. 


\section{Introdução}

A partir da análise da série Peixonauta (2009), desenho animado que integra a programação do canal de TV por assinatura Discovery Kids, vinculado ao grupo Discovery Communications Inc., mais conhecido como Discovery Channel $^{1}$, buscamos destacar como algumas problemáticas ambientais são apresentadas às crianças, bem como discutir como são delineadas, nesta série, algumas identidades preservacionistas. Salientamos que o canal Discovery Kids Brasil, cuja sede é Miami (EUA), está em operaçáo na América Latina desde o ano de 1998, e há uma série de indicaçôes ${ }^{2}$ de que se trata do canal infantil mais assistido no Brasil (o Disney Channel ocuparia a $3^{\text {a }}$ posição). Segundo indica Gardin (2007), cerca de 14 milhóes de crianças assistiriam a esse canal, que opera ininterruptamente por 24 horas.

Assim sendo, argumentamos que o Discovery Kids tem um importante impacto na produção/invenção de identidades infantis, pois, como indicaram analistas culturais, tais como Douglas Kellner (2001) e Henry Giroux (1995; 2003), ao desenvolverem análises sobre as corporações que produzem, por exemplo, os filmes hollywoodianos, as personagens das séries deste canal televisivo integram uma verdadeira teia de produtos, que inclui bonecos, jogos variados, séries de livros (que recontam os episódios apresentados na TV, que também podem ser revistos no You Tube), além de livros para colorir, CDs que reproduzem as músicas que caracterizam os personagens, DVDs (que igualmente reprisam os episódios apresentados na TV), material escolar e artigos para a composição de festas infantis.

Cabe registrar, ainda, que, nas diferentes séries apresentadas na programação do Discovery Kids, é sempre afirmada a intenção de colocar em destaque temáticas, valores e habilidades tidas, de muitas formas, como importantes a um adequado desenvolvimento infantil. Assim, algumas séries se apresentam como voltadas à valorização de uma boa alimentação e à prática de exercícios físicos, dispondo-se, igualmente, a expor as crianças a um mundo de diversidade racial $(3,2,1$. Vamos:); outras destacariam valores tais como honestidade, persistência, responsabilidade e a capacidade de perdoar, também celebrando a aceitação à diferença (Milly e Molly e Wow! Wow! Wubbzy!); outras, ainda, se dispóem a promover o gosto pela leitura (Pinky Dinky Doo), ou o amor às viagens (Toot \& Puddle), mas também à dança (Angelina Ballerina), bem como à ciência (Sid, o cientista), ou a ensinarem a língua inglesa (Word World). 
Nesse sentido, é importante destacar a proposta da emissora, enunciada no site Tudo em foco sobre a sua programação $0^{3:}$ "[...] oferecer desenhos animados 24 horas por dia para que as crianças fiquem felizes e seus pais despreocupados" (PROGRAMAÇÃO, 2012). Para o referido site, "[...] toda a criança necessita de lazer e diversão para que possa crescer saudável e sem traumas relativos à infância" (PROGRAMAÇÃO, 2012).

A animação Peixonauta (2009), que examinamos neste artigo, tem como foco principal as diversas problemáticas ambientais contemporâneas, entre elas: a introdução de espécies exóticas e domésticas na natureza, e o modo como essa prática afeta o meio ambiente; a poluição das águas, solo e ar; e certos fenômenos "naturais" - enxurradas, secas prolongadas, tremores de terra, por exemplo - que afetam (e perturbam) a vida do planeta. Mas é interessante registrar, também, que muitos episódios dessa série dão destaque e associam problemas ambientais a açóes inconsequentes dos seres humanos, ao mesmo tempo em que conferem importância à tecnologia para a solução destes problemas. Assim, a partir da intersecção de campos teóricos como a Educação, a Educação Ambiental, os Estudos Culturais e os Estudos de Mídia, o objetivo central deste estudo é ressaltar como, através da série televisiva de animação Peixonauta (2009), ensina-se quais açôes e quais problemas devem ser considerados relativamente aos chamados ambientes naturais. Argumentamos que essa série que intenciona ensinar às crianças atitudes "positivas" em relação ao meio ambiente, bem como formar sujeitos mais atentos às problemáticas ambientais, pratica aquilo que chamamos de "Educação Ambiental corporativa". Salientamos que a emissora informa, de várias maneiras, estar atenta às problemáticas ambientais, e que o seu próprio logotipo (um grande elo de cor amarela que envolve as letras " $\mathrm{d}$ " - em cor amarela e assentada sobre um fundo azul - e um "k" verde brilhante) - ao qual, em alguns programas, é acrescida a imagem de um globo terrestre em movimento (DISCOVERY, 2011) -, contém apelos na direção indicada ${ }^{5}$. Além disso, é possível dizer que outros desenhos e programas veiculados pela Discovery Kids remetem a aspectos destacados por educadores ambientais contemporâneos. Dentre esses, se destaca a Campanha Viva o Verde (DISCOVERY, 2012) apresentada entre 2011 e 2012, nos meses que antecedem o Dia Mundial do Meio Ambiente (abril e maio), na qual foram vinculadas mensagens acerca da importância do meio ambiente. Tais mensagens, que assumem uma configuração bastante aproximada de vinhetas, são protagonizadas por todas as personagens dos desenhos ou programas exibidos por este canal televisivo, sob a liderança do 
mascote da emissora: Doki, um simpático cachorrinho branco que possui uma pinta preta em uma de suas orelhas. A vinheta consiste na apresentação de uma série de imagens que reproduzem elementos da natureza, enquanto é entoada a canção "Somos necessários" (DISCOVERY, 2012) cuja estrofe final sumariza do seguinte modo tudo o mais que é dito na extensa letra dessa canção:

Sentado embaixo da mangueira, Debaixo de uma enorme mangueira. Pensando em tudo que pude ver. Olhe só a que bela conclusão eu cheguei! Todos somos necessários! Árvores, flores, pássaros, sapos. Todos, todos... Todos somos necessários! Para cuidar da vida, para salvar o planeta. Todos somos necessários! (Refrão $2 \mathrm{x}$ ). (DISCOVERY, 2012).

Mas questôes relacionadas a problemáticas ambientais também são abordadas nas séries: $O$ pequeno príncipe, baseada no livro original de Antoine de Saint-Exupéry, incluída na programação da emissora em novembro de 2011, Octonautas, Sid, o cientista, Dino Dan, Willa e seus animais, entre outras. (DISCOVERY. 2012).

Salientamos, no entanto, que não se pretende, com este artigo, validar açóes, proposiçóes ou atitudes ambientalistas veiculadas no canal Discovery Kids - que, aliás, informa explicitamente ter preocupaçóes ecológicas. Tampouco se buscará apresentar a série Peixonauta (2009) como um "modelo" para sugerir qualquer procedimento que venha a integrar as açóes educativas escolares. As preocupaçóes analíticas assumidas nas perspectivas culturalistas, nas quais nos inspiramos para realizar o estudo do qual deriva este artigo, direcionam-se a estimular o questionamento dos efeitos produtivos decorrentes de exemplificaçóes/açóes/proposiçóes assumidas, por exemplo, por instâncias culturais tais como a mídia e artefatos tais como a televisão. Buscamos, igualmente, indicar, a partir dessa perspectiva, como tais instâncias e artefatos atuam na produçáo/invençấo de formas bastante naturalizadas de pensar o mundo, a natureza, o ambiente e os sujeitos contemporâneos.

\section{Peixonauta: apresentando a animação}

A série brasileira de animação Peixonauta (2009) estreou no canal Discovery Kids em 20 de abril de 2009, tendo, até o momento, 52 episódios 
com 11 minutos de duração cada, que integra a programação diária do canal de TV por assinatura Discovery Kids em três diferentes horários ${ }^{6}$, sendo também veiculada na TV aberta, no Canal SBT, no programa Carrossel Animado. Atualmente, Peixonauta é exibido em 67 países $^{7}$ e traduzido para vários idiomas, como espanhol, inglês, árabe e turco. A série pode ser adquirida sob a forma de DVDs (sete volumes já foram lançados) e pode ser assistida, gratuitamente, pela internet (no You Tube).

Trata-se de uma série produzida inteiramente no Brasil pela TV PinGuim ${ }^{8}$, com patrocínio do BNDES, Bunge, Secretaria do Audiovisual do Ministério da Cultura e da Agência Nacional de Cinema (ANCINE), em associação com o canal Discovery Kids. Célia Catunda e Kiko Mistrorigo são os criadores da série, que se endereça a crianças de 3 a 7 anos. A trilha sonora, assinada por Paulo Tatit, do Palavra Cantada, traz ritmos brasileiros, tais como o samba, o baião, o forró, bem como tradicionais cançôes populares.

Segundo o site da produtora TV PinGuim (2012),

[...]. Desde a sua estreia, em abril de 2009, a série Peixonauta - está entre os primeiros lugares de audiência no Discovery Kids, sendo também o programa mais assistido em toda a TV paga. A série estreou no SBT em maio de 2011. - Peixonauta - foi premiada pela APCA (Associação Paulista de Críticos de Arte) como melhor programa infantil de 2009. Recebeu também o prêmio Prix Jeunesse Latino Americano, melhor programa de ficção, categoria infantil. Atualmente, a TV PinGuim está produzindo [...] o longa metragem Peixonauta, além da segunda temporada da série, com novos 52 episódios.

Todos esses aspectos referidos são indicativos da produtividade desta animação, que inclusive já foi transformada em uma peça de teatro, sob a denominação "Peixonauta, da TV para o teatro", encenada nas principais capitais brasileiras. Além disso, a marca Peixonauta estampa 300 produtos de 20 empresas diferentes, aspecto também apresentado como indicativo da sua popularidade. Como é possível ver, não cessam de proliferar os elos que ligam as personagens dessa série às crianças que a assistem, a partir de uma contínua diversificação e ampliação dos artefatos que reproduzem suas personagens e histórias. Não cessam, também, de aumentar os ganhos/lucros obtidos por 
patrocinadores, empresários/as, atores/atrizes, comerciantes, citando-se apenas alguns dos sujeitos e algumas das instâncias que lucram com a comercialização da série e dos produtos a ela vinculados.

Feitos estes esclarecimentos mais introdutórios, destacamos, ainda, que os episódios da série se centram, todos eles, na resolução de um problema, o que fica marcado nos títulos dos episódios, sempre iniciados com a expressão “O caso do/a(s)...”. De acordo com Morais, Garíglio e Aguiar (2011), vários são os desenhos animados do canal Discovery Kids que apresentam um estilo de narrativa considerado clássico (porque oriundo da literatura do século XVIII e que influenciou a narrativa do cinema do século XX), contendo a seguinte estrutura: a) apresentação do problema; b) busca pela solução do problema; c) soluçáo do problema. Os autores afirmam, ainda, que os 11 minutos de duração do desenho são

[...] suficientes para a apresentação do problema, que é sempre relacionado a questôes de sustentabilidade; para a busca de sua solução, em que o "Peixonauta" conta com a ajuda de seus amigos do Parque das Árvores Felizes e da bola ${ }^{9} \mathrm{POP}$ e, posteriormente, para a apresentaçáo da solução do problema propriamente dita. (MORAIS, GARÍGLIO; AGUIAR, 2011, p. 143).

O chamamento à aventura ou à realização de uma missão também é feito a partir da trilha musical, que confere um "tom" de brasilidade à animação. Vejamos como isso se faz a partir da letra da toada, adaptada por Paulo Tatit para a abertura e o encerramento de todos os episódios:

Peixonauta, Marina e Zico. Juntos com tantos amigos. Êêo, hoje tem mais uma aventura. Êêô, hoje tem mais uma missão! (refrão 2 x) Ou será um mistério. Vem a POP indicar. Pra entender o mistério. Todo mundo vai dançar. Peixonauta, bate palma. Os amigos batem o pé. Nós queremos uma pista. A POP diz qual é. (DISCOVERY, 2011).

As aventuras se passam em um local imaginário e extenso cujo nome é Parque das Árvores Felizes. Neste Parque, estão representados os mais variados ambientes - planícies, montanhas, florestas, lagos, mares, desertos. Mas, há, 
também, nesse Parque, alguns ambientes peculiares, tais como a Floresta da Preguiça, a Floresta das Aventuras, a Ilha dos Macacos e o Lago do Descanso, locais em que vivem alguns dos protagonistas da série. Vive lá, também, uma multiplicidade de espécies diferentes - aspecto que será analisado em profundidade ao longo deste artigo.

É importante indicar, ainda, que este Parque dispóe de um muito eficiente sistema de controle (e este parece ser um importante destaque ou alerta para se pensar como as práticas ambientais, ainda hoje, necessitam estar atreladas a legislaçóes e diretrizes de ordens superiores) coordenado pela Organização Secreta para Total Recuperação Ambiental (Ostra), junto à qual operam três agentes (todos eles peixes) que acionam mecanismos para indicar a ocorrência (e auxiliar na solução) de problemas que nele surjam. O principal agente é Peixonauta, que dá nome à série, representado como um estranho peixe que se vale intensamente das tecnologias, tanto para circular fora dos ambientes aquáticos quanto para resolver os problemas que surgem no Parque. Peixonauta usa uma espécie de escafandro cheio d'água (o Bublex), que o deixa bastante semelhante a um astronauta, quando está fora do Lago do Sossego, seu habitat natural. Os outros dois agentes da Organização vivem no mesmo lago, sendo eles: Rosa, um peixe-fêmea corde-rosa, representada como extremamente coquete; e Chumbo Feliz, peixe que vive nas profundezas do lago, de cor cinzenta e robusto, configurado como muito velho e muito sábio, que se expressa através de charadas. $\mathrm{O}$ sistema de detecção de problemas no Parque é sempre acionado pela Ostra, representada como uma concha que contém uma pérola/bola multicolorida - a Pop. Ambas se abrem a partir de uma espécie de ritual que inclui batidas de mãos e de pés, acionadas a partir de um tema musical que convoca as personagens da série e a audiência a se integrar a essa ação. A funçáo da Pop é liberar objetos que funcionam como indícios/pistas para que os/as agentes e investigadores/as que vivem no Parque possam localizar e resolver os problemas identificados, ação na qual se empenham, além de Peixonauta, Marina, Zico e Dr. Jardim. Aliás, cabe registrar que este sistema funciona de forma perfeitamente sincronizada, desde que sejam cumpridos os ritos e as práticas que permitem o seu acionamento.

Marina é uma menina de oito anos de idade, extremamente comprometida com a conservação do Parque, e que está sempre atenta à possibilidade de nele ocorrerem problemas ambientais. Pode-se dizer que ela incorpora qualidades 
que seriam desejáveis encontrar em sujeitos "ecologicamente corretos" - atençáo, interesse, cuidado e operatividade vigilante diante do ambiente natural. Outro personagem importante das histórias é Dr. Jardim, avô de Marina e veterinário do Parque, usualmente requisitado para fornecer explicaçóes científicas sobre os problemas detectados. Seu laboratório, que dispóe de um suporte tecnológico invejável, localiza-se na parte superior de um enorme pé de feijão, que funciona como uma espécie de torre de vigilância, permitindo uma visão ampliada do Parque.

Já Zico é um jovem macaco brincalhão sempre em busca de um cacho de bananas, que vive na Ilha dos Macacos (localizada no Lago) e que está sempre dividido entre uma brincadeira e o comprometimento com as tarefas investigativas realizadas por seus amigos. Vivem, ainda, no Parque os dois irmãos gêmeos de Marina, Pedro e Juca, que, por desconhecerem práticas ambientais tidas como adequadas, muitas vezes, prejudicam a vida no Parque.

\section{Abordagem teórico-metodológica}

O corpus analítico do presente artigo compóe-se de 30 episódios, de um total de 52, escolhidos por evidenciarem quatro grandes temáticas ambientais: a) reciclagem de materiais; b) introdução de espécies exóticas; c) poluição; d) mudanças climáticas e problemas associados (escassez de água, aumento médio de temperatura, etc.). Os episódios foram analisados desde a perspectiva dos Estudos Culturais e dos Estudos de Mídia - o que equivale dizer que pressupomos que a mídia é, na contemporaneidade, uma das principais instâncias de produção e de circulação de significados (acerca de nós mesmos e do ambiente que nos cerca) e que, portanto, ela atua de maneira pedagógica por meio de nossa colaboração e de nosso engajamento (STEINBERG, 1997; FISCHER, 2001; STEINBERG; KINCHELOE, 2004). Da mesma forma, a perspectiva teórica aqui assumida também pressupóe o questionamento e a problematização daquilo que é constantemente produzido e naturalizado por instâncias e artefatos culturais diversos - assim, questionamos, por exemplo, a eleição de alguns temas ecológicos e ambientais para incentivar o chamado "consumo responsável" de desenhos animados, bem como examinamos com atenção a tendência à corporativização das preocupaçôes ambientais para crianças e pais mundo afora (preocupaçóes, essas, mostradas em Peixonauta como ingênuas, triviais, de fácil resolução). 
Há uma espécie de onipresença de temáticas que compreendem o ambiente e a natureza nas mídias. Vários trabalhos acadêmicos vêm demonstrando isso há vários anos, seja na publicidade (AMARAL, 2000), seja no cinema (KINDEL, 2007), nos livros infantis e infanto-juvenis (WORTMANN, 2007), nas revistas de grande circulação nacional (SCHWAAB, 2008), na TV (ANDRADE, 2003; DUTRA, 2009), nos jornais (SILVA, 2005; KIRCHOF; WORTMANN; BONIN, 2011; SAMPAIO, 2012), no cinema (RIPOLL; MARCELLO, 2011), nas campanhas publicitárias de inúmeras empresas (FERREIRA, 2007; PAIM, 2011; PAIM; RIPOLL, 2011), etc. Nesse sentido, Pereira (2010, p. 92) afirma que o chamado "desenvolvimento sustentável" está na ordem do dia tanto em termos midiáticos quanto em termos ambientais e corporativos, sendo "o discurso padrão das organizaçōes".

De acordo com Pereira (2010), as preocupaçóes ecológicas envolvendo a sustentabilidade emergem de modo organizado nos anos 1970 (em funçáo da primeira Conferência Internacional sobre o Meio Ambiente, promovida pela Organização das Naçóes Unidas em Estocolmo, 1972), mas se tornam mais visíveis no final dos anos 1980 - notadamente, em um relatório ${ }^{10}$ da Comissão Mundial sobre Meio Ambiente e Desenvolvimento das Naçôes Unidas, intitulado Nosso Mundo Comum (1988) e, posteriormente, nas muitas conferências fartamente noticiadas pela mídia a partir dos anos 1990 (a Rio 92, a Kyoto 97, a Estocolmo 2001, etc.). Para Pereira (2010), as preocupaçóes envolvendo a ação antrópica sobre o aquecimento global e a perda da biodiversidade começaram a ser veiculadas nos meios de comunicação motivadas por cientistas de diferentes áreas do conhecimento, pelos movimentos ambientalistas, por organizaçóes náo governamentais de defesa da natureza, etc. Mas, para Lipovetsky e Serroy (2009), a onipresença da ecologia (e, também, em alguma medida, da ficçáo científica) na TV e no cinema a partir dos anos 1970 ocorre, justamente, porque se trata da materializaçáo, na "telinha" e na "telona", de alguns dos principais medos humanos:

Desde a metade dos anos 1970, os processos movidos contra a civilizaçáo tecnocientífica não cessaram de se desenvolver. Ela devia supostamente trazer segurança, liberdade e bem-estar: ei-la assimilada por seus detratores ao inimigo número um, que ameaça ser um obstáculo ao futuro durável de nossos filhos. "A casa pega fogo": a tecnociência é vista como a máquina diabólica que, 
indiferente às consequências a longo prazo, nos precipita diretamente no abismo. Geradora de conforto imediato, ela é também cada vez mais produtora de medos ligados à degradação da ecosfera, a riscos irremediáveis que pesam sobre a humanidade e o planeta. No momento em que o mercado e o hiperconsumo parecem instalar o indivíduo numa referência exclusiva ao presente, as inquietaçóes relativas ao futuro planetário nunca foram tão fortes. Depois da euforia do progresso, "os danos do progresso"; depois do êxtase da libertação, o medo do futuro. A afirmação e a difusão dos valores ecologistas são a tradução disso. $\mathrm{O}$ medo ancestral gira agora em torno de "uma nova geraçáo de riscos" - ameaças industriais, tecnológicas, sanitárias, naturais, ecológicas. (LIPOVETSKY; SERROY, 2009, p. 178).

A "novidade" talvez seja a apresentação de tais medos de modo disseminado e para públicos cada vez mais jovens, por meio da TV e do cinema para crianças. Dessa forma, produzir-se-ia a naturalização dos medos relativos à natureza e ao ambiente, bem como a instauração do que Andrade (2003) chama de "otimismo sustentável":

No início dos anos 70 imperava, tanto no Brasil como no contexto mundial, um sentimento de pessimismo quanto à capacidade da civilização moderna em se adequar às demandas ecossistêmicas. Acreditava-se que a degradação ambiental seria irreversível e os limites do crescimento econômico haviam excedido os índices aceitáveis. Posiçóes ambientalistas mais radicais e posturas tecnocráticas moderadas ocupavam a cena central, em que a cooperação e o diálogo tornavam-se escassos. [...]. A partir do final dos anos 80, foi sendo estabelecida mundialmente uma ideia-força que teve condiçóes de aglutinar todos os múltiplos anseios e perspectivas formulados a nível global: a noção de desenvolvimento sustentável. Forja-se, daí em diante, o otimismo da sustentabilidade, que irá se arraigar por diversos setores sociais, inclusive o espetacular ecológico. (ANDRADE, 2003, p. 161-162). 
O "otimismo da sustentabilidade" é um aspecto muito interessante, já que acaba por inundar a programação televisiva das últimas décadas, bem como acaba por compor as estratégias de marketing de empresas e instituiçôes governamentais e não governamentais diversas (ligadas ou não ao ambiente). A isto, se chama "Educação Ambiental corporativa" ou, ainda, "Educação Ambiental empresarial", que surgiu como uma resposta das empresas às pressões exercidas pelos órgãos que compóem o Sistema Nacional de Meio Ambiente (Sisnama), bem como às pressões das organizações ativistas diante da degradação ambiental (PEDRINI; PELLICCIONE, 2008). Segundo os referidos autores (PEDRINI; PELLICCIONE, 2008), a Educação Ambiental corporativa funciona para promover adequaçôes imprescindíveis ao atendimento de Termos de Ajustes de Conduta (TAC), como forma de evitar ou reparar incidentes ou acidentes ambientais ou, ainda, como forma de obtenção de certificaçôes e prêmios ambientais que representam diferenciais competitivos de mercado - servindo, portanto, como estratégias de marketing empresarial e, em última análise, como marketing verde ${ }^{11}$.

Steinberg e Kincheloe (2004) apontam as grandes corporaçóes contemporâneas - isto é, grandes conglomerados empresariais tais como McDonalds, Disney, Viacom, Warner, Sony e, certamente, poder-se-ia incluir, neste rol, a Discovery Networks Inc. - como "os" educadores deste século, bem como organizaçóes que criaram currículos culturais eminentemente comerciais, "[...] que operam náo para o bem social, mas, para o ganho individual” (STEINBERG; KINCHELOE, 2004, p. 15). Segundo os autores, os ensinamentos produzidos e veiculados por tais corporaçóes procuram criar padróes de consumo, construir determinadas identidades (de gênero, de classe, de raça/etnia, etc.) e, sobretudo, produzir determinados saberes na direçáo do controle e da regulaçáo social. A associação de tais corporaçóes com os discursos ecológicos e ambientalistas é, na verdade, apenas mais uma estratégia de fabricaçáo e de captura de consumidores supostamente "responsáveis" (cada vez mais individualistas, cada vez mais superficiais, cada vez mais pensadores do instantâneo e do fugaz).

\section{Problemáticas ambientais em Peixonauta}

Fischer (2001, p. 12) afirma que "[...] a TV torna visíveis para nós uma série de olhares de pessoas concretas - produtores, jornalistas, atores, roteiristas, 
diretores, criadores, enfim, de produtos televisivos - a respeito de um sem número de temas e acontecimentos". Segundo a autora, ao assistirmos à TV, "[...] é possível enxergar ali muito do que somos (ou do que não somos), do que negamos ou daquilo em que acreditamos, ou ainda do que aprendemos a desejar ou a rejeitar ou simplesmente a apreciar" (FISCHER, 2001, p. 12). Nesse sentido - e pensando na série Peixonauta -, poder-se-ia afirmar que os problemas ambientais (ora causados pelos gêmeos Pedro e Juca, ora causados por eventos naturais, ora sem causa aparente) sáo mostrados (pelos criadores, diretores e roteiristas da animação) como "facilmente solucionáveis". Não há, via de regra, conflitos ou sofrimentos envolvidos: as personagens solucionam "brincando" (e cantando, batendo palmas, rindo, etc.) todas as situaçóes apresentadas. Essa animaçáo operaria, assim, na direçáo da naturalizaçáo/ banalizaçáo dos problemas ambientais - e, portanto, provocaria o seu apagamento.

A sutileza das "problemáticas" ambientais mostradas (e que precisariam ser resolvidas por Peixonauta, Marina e Zico) reforça o argumento da naturalização: às vezes, trata-se de questôes presentes no dia a dia dos telespectadores (poluição das águas, do ar, do solo; reciclagem, etc.), mas, em certas ocasióes, trata-se de questôes de fundo antropocêntrico, tal como o "sumiço das cestas de piquenique" (quando os animais começam a procurar alimentos nas cestas de piquenique dos frequentadores do Parque das Árvores Felizes) e, também, o "caso da bagunça das marmotas" (quando elas começam a invadir todos os ambientes do Parque, inclusive o Laboratório do Dr. Jardim).

Pedro e Juca representariam sujeitos que desconhecem os efeitos que muitas de suas ações podem ter sobre o ambiente - sáo sujeitos a serem conscientizados, ensinados (tal como as crianças que assistem o desenho) e cujas açóes sáo, invariavelmente, condenáveis, inadequadas. As atitudes dos gêmeos não são mostradas como "maléficas", mas, sobretudo, como inconsequentes e ignorantes (por exemplo, quando começam a aparecer marmotas por todos os lugares, no Parque, logo se percebe que isso foi causado pelo entupimento das tocas com as bolinhas jogadas por Pedro e Juca). Mas, ao final de cada episódio, há sempre momentos de "conversáo" desses sujeitos, bem como de comprometimento com as açóes de resoluçáo dos problemas que causaram. Já Zico, Peixonauta e Marina representam sujeitos ativamente envolvidos com os problemas ambientais e sabedores do que precisa ser feito para contorná-los, corrigi-los, etc. 
Dr. Jardim representa a figura do especialista, detentor do conhecimento acadêmico-formal e técnico sobre os ambientes naturais - quando consultado, ele fornece as explicaçóes de que a ciência dispóe sobre os problemas surgidos. Já o agente Chumbo Feliz detém outros tipos de conhecimento, relacionados, em grande medida, com o que usualmente se representa como "conhecimento ancestral" ou, ainda, como "sabedoria inata" que uma intensa (e antiga) vivência ambiental produziria.

\section{A natureza em Peixonauta: outros apontamentos}

Num primeiro momento, pode-se afirmar que a natureza representada ${ }^{12}$ no/pelo desenho animado em questão é "genérica", constituindo-se, meramente, em um cenário para o desenvolvimento das açôes de Marina, Peixonauta e Zico. Nesse sentido, o Parque-cenário contém uma espécie de síntese dos ambientes naturais de todo o planeta, que lá estariam dispostos "lado a lado" em um entrelaçamento processado sem maiores consequências nem aparentes dificuldades. Além disso, tais ambientes sáo mostrados mesclados e reunidos sem um cuidado mais detido acerca de noçóes tais como as de cadeia alimentar, e espécies de diferentes hábitos e habitats conviveriam harmonicamente. Em um dos episódios, notadamente, é possível perceber girafas, alces, zebras, corujas, lobos, antas, emas, patos, lobos, elefantes e outros seres comemorando, alegremente (há, inclusive, balóes na naturezacenário!), a resoluçáo do caso em torno do qual gira este episódio, bem como a descomplicada limpeza do Parque procedida pelas personagens da história.

Tal simplificação talvez possa ser melhor entendida a partir das consideraçóes feitas por Morais, Garíglio e Aguiar (2011) que analisaram a animação em questão desde a perspectiva da teoria da Gestalt. Os autores afirmam que Peixonauta possui uma linguagem visual bastante simples e de fácil compreensão por se utilizar, com abundância, de formas geométricas básicas (círculos, retângulos, triângulos, quadrados, elipses) na composição dos cenários e das personagens, bem como do recurso da "borda visual" muito evidente e fechada. Segundo os autores, o fato de as personagens apresentarem maiores informaçóes visuais do que os cenários "[...] contribuiria para uma fixação maior do olhar durante a busca visual” (MORAIS; GARÍGLIO; AGUIAR, 2011, p. 150).

Assim, em uma das sequências de abertura da animação - sequência, esta, que se repete em todos os episódios analisados -, verifica-se certa tendência à 
padronizaçáo, à fixidez e ao ordenamento do "cenário natural”: cerca de quatro ou cinco tipos de árvore, com copas ovais, circulares ou arredondadas, são repetidos à exaustão em cada frame da animação. Trata-se de uma natureza geometricamente posicionada e alinhada, fixa, que integra um "pano de fundo", em tons de verde e marrom, às açôes de Peixonauta e seus amigos. E, assim, pode-se dizer que a prevalência de elementos relativos à técnica da produção da animaçáo parece ser determinante para que a natureza representada em Peixonauta seja configurada como relativamente simples e, portanto, como capaz de ser entendida sem grandes dificuldades pelas crianças pequenas, a quem se endereça, especialmente, a animaçáo. Mas cabe ainda indicar a semelhança de algumas paisagens aéreas focalizadas na abertura dos episódios com a região da Baía da Guanabara, no Rio de Janeiro, bem como a frequência com que são incluídas nos episódios espécies bastante representativas de paisagens brasileiras - araras e palmeiras, por exemplo -, ao mesmo tempo em que a trilha sonora toca sambas quando é focalizada uma paisagem de praia (tal como sucede no episódio denominado "O caso dos duendes luminosos", por exemplo).

Outro aspecto interessante a ser apontado diz respeito à presença da tecnologia a auxiliar as personagens na soluçáo dos "problemas" ambientais apresentados. Por exemplo, em "O caso dos carneirinhos", é com o auxílio de todas as personagens e, especialmente, da tecnologia que as personagens constroem uma roda d'água para permitir que a seca que atinge os carneiros do alto da montanha seja resolvida. A tecnologia permite, ainda, que as personagens Rosa, Peixonauta e Marina se comuniquem, tal como é possível ver, neste mesmo episódio, valendo-se eles ora de um artefato semelhante a um microcomputador, ora através de um especial relógio, ora por meio de uma espécie de comunicador. Aliás, o protagonista da animação não é um peixe qualquer, mas um ser híbrido: ele não está preso ao rio (a tecnologia "o libertou" do rio, ampliando sua área de ação, importância e abrangência), e ele é visto, invariavelmente, "pairando", acima de todos os envolvidos, utilizando computadores, sensores, telas, televisores, etc.

Outro importante aspecto a ser considerado é que as açóes empreendidas pelos animais da animaçáo sáo sempre conciliatórias e voltadas para a resoluçáo de problemas - náo há conflitos ou disputas de qualquer tipo, apenas integraçáo harmônica entre os envolvidos. $\mathrm{O}$ fato de vermos esquilos, capivaras, girafas, antas e ariranhas misturados e ocupando os mesmos ambientes reforça a ideia de que a natureza estaria, essencialmente, em harmonia. Além 
disso, é frequente vermos as personagens "relaxadas" e contentes - por exemplo, em um dos episódios (“O caso da... Qual é o caso mesmo?"), a anta "conversa" com Peixonauta e seus amigos, e veem-se, em uma das sequências, a ariranha apoiada na margem do rio (bastante descontraída, como que aproveitando...) e a capivara brincando com uma bolinha presa a uma raquete. Todos sorriem, felizes, e tudo parece em ordem no Parque das Árvores Felizes.

Ao analisar as produçóes da Disney Company voltadas ao público infantil, Giroux (2003) enfatiza que estaria em ação naquela corporação, através de seus múltiplos produtos e serviços, uma "política da inocência" que editaria os conflitos e as negociaçóes inerentes aos diversos grupamentos humanos. Nesse sentido, a inocência seria um discurso bastante estratégico:

A Disney deu um novo significado à política da inocência, como uma narrativa para moldar a memória pública e para produzir um "corpo geral de identificaçóes" que promova uma versão empacotada e higienizada da história norte-americana. A inocência também serve como um dispositivo retórico, que limpa a imagem da Disney da influência confusa do comércio, da ideologia e do poder. Em outras palavras, a associação estratégica da Disney com a infância, um mundo limpo de contradiçóes e livre da política, representa não apenas o apelo básico de seus parques temáticos e filmes, como também proporciona um modelo para definir a cultura empresarial separada da influência do poder empresarial. (GIROUX, 2003, p. 134).

Podemos pensar, assim, que a articulação desses dois discursos - o ambiental e o da inocência - em "Peixonauta" e, também, em uma série de outras iniciativas do Discovery Networks (já citadas no presente artigo) funcionaria como uma espécie de salvaguarda às açôes comerciais da empresa (orientadas, eminentemente, pelo lucro). Dessa forma, tal articulação também reforçaria o status e a autoimagem da empresa perante os públicos, bem como promoveria a captura de mais e mais consumidores. Mas Giroux (2003) vai além, ao afirmar - ainda em relação à Disney - que

[...] reconhecer que a [empresa] tem um interesse político de criar determinada ordem moral, favorável a seus 
interesses comerciais, levanta questóes fundamentais sobre aquilo que ela ensina, de maneira a produzir os significados, os desejos e os sonhos pelos quais tenta alistar jovens e adultos na sua visão de mundo. (GIROUR, 2003, p. 137).

\section{Considerações finais}

Caberia ainda afirmar, à guisa de conclusão, que não se pretendeu, neste artigo, esgotar o tema da corporativização, em escala global, das preocupaçôes ambientais para crianças e pais. E, tampouco, "demonizar", destruir, invalidar ou denunciar as açôes intencionalmente nefastas contidas nas propostas de entretenimento (e de ensinamento) para crianças postas em circulaçâo através do Discovery e de seus veículos associados. Juntamo-nos a Giroux (2003, p. 138) para afirmar que as grandes corporaçóes não estão, simplesmente, produzindo um entretenimento inofensivo, notícias desinteressadas ou acesso ilimitado à era da informação, nem estáo afastadas dos domínios do poder, da política e da ideologia. Para o autor, o reconhecimento do prazer que essas corporaçóes (e seus programas televisivos) nos proporcionam não deve nos cegar ao entendimento de que elas lidam com algo mais do que a produçáo de entretenimento e de diversão.

Nossas análises nos permitiram entender que esta emissora televisiva se rendeu, de muitas formas, aos apelos da "onda verde", que parece ter tomado conta da mídia e de outras instâncias de produçáo da cultura na contemporaneidade. Mas não desconsideramos, também, ser essa uma das muitas formas através das quais se têm processado interaçóes entre as crianças e o mundo natural que, às vezes, parece estar táo distante delas.

Talvez seja possível retomar considerações feitas Kirchof, Wortmann e Bonin (2011) acerca da emergência de um ambientalismo midiático, uma versão híbrida de proposiçôes de consumo, de técnicas de animação e de açôes de conscientizaçáo ambiental que estaria granjeando espaços cada vez maiores nas produçôes culturais midiáticas. E a série Peixonauta nos parece ser um exemplo bem-sucedido disso. 


\section{Notas}

1 Integram esta corporaçáo, além do Discovery Kids, mais outros 12 canais televisivos, entre os quais estão: Discovery Channel; Animal Planet; People+Arts; Discovery Travel \& Adventure; Discovery Home \& Health; Discovery Travel \& Living, programas transmitidos em mais de 33 idiomas, que atingem cerca de 160 territórios, alcançando uma audiência de cerca de 1 bilhão de telespectadores (GARDIN, 2007).

2 Entre os sites que fazem tal destaque estão: <http://www.rd1audiencia. $\mathrm{com} /$ televisao/audiencia-da-tv-paga-discovery-kids-e-lider/ $>$; $\langle$ http:// portaldoplimplim.wordpress.com/2012/01/15/discovery-kids-lideraa-audiencia-da-tv-paga-em-2011/>; <http://www.anmtv.xpg.com.br/ confira-a-audiencia-dos-canais-infantis-no-mes-de-maio/>; <http:// noticiasdatvbrasil.wordpress.com/2011/11/25/discovery-kids-e-o-canalmais-assistido-da-tv-paga-em-2011/>. Acesso em: 25 jan. 2012.

3 Para maiores informaçôes ver também o site <http://discoverykidsbrasil. uol.com.br/>.

4 Disponível em: <http://www.discoverybrasil.com/>.

5 Consideramos, também, que as cores utilizadas no logotipo intencionam conferir uma marca de brasilidade a este canal televisivo.

6 Os episódios são apresentados nos seguintes horários: 11h30min, 19h30min e $0 \mathrm{~h} 30 \mathrm{~min}$.

7 Entre esses, estáo Canadá, Estados Unidos da América, Coréia do Sul e Nova Zelândia. No mercado internacional, esta série receberia denominaçóes tais como Peztronauta (2012) ou Fishtronaut (2012).

8 A TV PinGuim é uma produtora paulistana que, há 20 anos, “[...] desenvolve e produz séries de animação para a televisão, o cinema, a internet e a telefonia celular" (TV, 2012). Maiores informaçóes no site: <http:// www.tvpinguim.com.br/>.

9 Não se sabe ao certo se é uma bola ou uma pérola multicolorida, em função de localizar-se no interior de uma ostra (que "materializa" a Organização Secreta para a Total Recuperação Ambiental - Ostra). Todos os sites já referidos náo levam em consideraçáo essa possibilidade. 
10 Esse Relatório ficou também conhecido como "Relatório Brundtland", já que a Comissão era dirigida por Gro Harlen Brundtland, então ex-primeira ministra da Noruega. Mais detalhes em: <http://www.onu.org.br/a-onuem-acao/a-onu-e-o-meio-ambiente/>.

11 De acordo com Paim e Ripoll (2011), marketing verde é uma estratégia de mercado que tem como objetivo criar ou realçar os benefícios de determinados produtos ou serviços de tal forma que estes sejam compreendidos como "diferentes" e "melhores" em relaçáo a outros produtos e serviços (e do próprio processo produtivo) que não apresentem uma preocupação com o meio ambiente. Dessa forma, além de o marketing verde servir como uma ferramenta útil para a diferenciação de um determinado produto que se pretende ecologicamente sustentável, e ao estímulo que essa diferença proporciona para o consumo de um ou outro produto, ele serviria também para reforçar a legitimidade da empresa, ao se adotar determinado processo de produção que se pretende sustentável.

12 O conceito de "representaçáo" aqui empregado refere-se à construção cultural de significados (referentes a grupos, práticas, comportamentos, instituiçóes, sujeitos, coisas, etc.) por meio da linguagem, tal como foi destacado por Hall (1997).

\section{REFERÊNCIAS}

AMARAL, Marise Basso. Natureza e representação na pedagogia da publicidade. In: COSTA, Marisa Vorraber (Org.). Estudos Culturais em Educação. 2. ed. Porto Alegre: Editora da UFRGS, 2000. p. 143-171.

ANDRADE, Thales de. Ecológicas manhãs de sábado: o espetáculo da natureza na televisão brasileira. São Paulo: Annablume, 2003.

DISCOVERY Kids Brasil. 2012. Disponível em: <http://discoverykidsbrasil. uol.com.br/>. Acesso em: 25 jan. de 2012.

FERREIRA, Maira. Problematizando as açóes educativas de uma empresa estatal. In: WORTMANN, Maria Lúcia; SANTOS et al (Org.). Ensaios em estudos culturais, educação e ciência. Porto Alegre: Editora da UFRGS, 2007. p. 297-312. 
FISCHER, Rosa Maria Bueno. Televisão e Educação: Fruir e pensar a TV. Belo Horizonte: Autêntica, 2001.

FISHTRONAUT. In: WIKIPÉDIA: a enciclopédia livre. 2012. Disponível em: <http://en.wikipedia.org/wiki/Fishtronaut>. Acesso em: 5 jan. 2012.

GARDIN, Edson. A produção televisiva infantil: Discovery Kids

Brasil: programa "Lazitown". 2007. XX f.. Dissertação (Mestrado em Comunicação) - Universidade Paulista. São Paulo, SP, 2007.

GIROUX, Henry. Ensinando o cultural com a Disney. In: GIROUX, Henry. Atos impuros: a prática política dos Estudos Culturais. Porto Alegre: Artmed, 2003. p. 127-147.

GIROUX, Henry. Memória e pedagogia no maravilhoso mundo da Disney. In: SILVA, Tomaz Tadeu (Org). Alienígenas na sala de aula. Petrópolis, RJ:Vozes, 1995 p. 132-158.

HALL, Stuart. A centralidade da cultura: notas sobre as revoluçóes de nosso tempo. Educação e Realidade. Porto Alegre, v. 22, n. 2, p. 15-46, jul./dez. 1997.

KINDEL, Eunice Aita Isaia. A natureza no desenho animado ensinando sobre homem, mulher, raça, etnia e outras coisas mais. In: WORTMANN, Maria Lúcia Castagna et al (Org.). Ensaios em Estudos Culturais, Educação e ciência. Porto Alegre: Editora da UFRGS, 2007. p. 223-235.

KIRCHOF, Edgar Roberto; WORTMANN, Maria Lúcia Castagna; BONIN, Iara Tatiana. Liçôes de sustentabilidade em um jornal brasileiro. Revista eletrônica do mestrado em Educação Ambiental. v. 2, p.116-128, jul./ dez, 2011.

KELLNER, Douglas. A cultura da mídia. Tradução de Ivone Castilho Benedetti. Bauru: Edusc, 2001.

LIPOVETSKY, Gilles; SERROY, Jean. A tela global: mídias culturais e cinema na era hipermoderna. Porto Alegre: Sulina, 2009.

MORAIS, Welerson R.; GARÍGLIO, Maria Inês; AGUIAR, Carolina Guimarães. A linguagem audiovisual nos desenhos animados infantis: o caso do "Peixonauta". In: XV CONGRESSO NACIONAL DE LINGUÍSTICA E FILOLOGIA, v. 15, n. 5, t. 1, 2011. Anais... Rio de Janeiro: CiFEFiL, 2011. p. 140-155. 
PAIM, Eduardo Garcez. Pedagogias culturais em açâo: um estudo das estratégias publicitárias da Aracruz Celulose. 2011. Dissertação (Mestrado em Educação) - Programa de Pós-Graduação em Educação da Universidade Luterana do Brasil. Canoas, RS, 2011.

PAIM, Eduardo Garcez; RIPOLL, Daniela. Educação Ambiental Corporativa: estratégias de marketing para a produção de sujeitos consumidores ambientalmente responsáveis. In: REUNIÁO ANUAL DA ASSOCIAÇÃO NACIONAL DE PESQUISA E PÓS-GRADUAÇÃO EM EDUCAÇÅ̆O, v. 34, 2011. Anais... Natal, RN: UFRN, 2011. p. 1-15.

PEIXONAUTA. Criação e Direção de Celia Catunda e Kiko Mistrorigo. Produção de Celia Catunda, Kiko Mistrorigo e Ricardo Rozzino. CoProdução de Discovery Kids. São Paulo: TV PinGuim; Discovery Kids, 2009. Série de desenho animado.

PEZTRONAUTA. In: WIKIPÉDIA: a enciclopédia livre. 2012. Disponível em: <http://es.wikipedia.org/wiki/Peztronauta>. Acesso em: 5 jan. 2012.

PROGRAMAÇÃO Discovery Kids: Sobre a programação da Discovery Kids. Tudo em Foco. São Paulo, 2 jun. 2009. Disponível em: <http://www. tudoemfoco.com.br/programacao-discovery-kids.html>. Acesso em: jan. 2012.

PEDRINI, Alexandre; PELLICCIONE, Nina. Educação Ambiental Empresarial no Brasil: uma análise exploratória sobre sua qualidade conceitual. Mundo e Vida, Niterói, v. 8, n. 1, 2008. Disponível em: <http://rearj.com/wp-content/ uploads/2008/09/artigoeaebmundoevidauff31102006_versao_pdf.pdfs.

PEREIRA, Ethel Shiraishi. Isso não tem importância: eventos e sustentabilidade na sociedade do espetáculo. Communicare: revista de pesquisa, São Paulo, v. 10, n. 1, p. 90-109, jan. 2010.

RIPOLL, Daniela; MARCELLO, Fabiana de Amorim. Notas sobre cinema-documentário: educação para o desenvolvimento sustentável. In: DEUTSCH-BRASILIANISCHES SYMPOSIUM NACHHALTIGE ENTWICKLUNG. v. 5, 18-22 jul. 2011. Anais... Stuttgart, Alemanha, 2011. p. 1-16.

SAMPAIO, Shaula Maira Vicentini. "Uma floresta tocada apenas por homens puros..." ou do que aprendemos com os discursos contemporâneos sobre a Amazônia. 2012. 296 f. Tese (Doutorado em Educação) - Universidade Federal do Rio Grande do Sul, Porto Alegre, RS, 2012. 
SCHWAAB, Reges Toni. Edições Verdes da revista Época: gramáticas ecológicas no jornalismo contemporâneo. In: ENCONTRO NACIONAL DE PESQUISADORES EM JORNALISMO DA ASSOCIAÇÃO BRASILEIRA DE PESQUISADORES EM JORNALISMO, v. 6, 2008. Anais... São Paulo: Umesp, 2008.

DUTRA, Manuel Sena. A natureza da mídia: os discursos da TV sobre a Amazônia, a biodiversidade, os povos da floresta. São Paulo: Annablume, 2009.

SILVA, Márcia Soares. Mídia e meio ambiente: uma análise da cobertura ambiental em três dos maiores jornais do Brasil. Comunicação em Agrobusiness e Meio Ambiente, v. 2, n. 2, jul. de 2005. Disponível em: < http://www.agricoma.com.br/revista/02/artigos/artigo12.asp>. Acesso em: 24 jan. 2012.

STEINBERG, Shirley. Kindercultura: a construção da infância pelas grandes corporaçôes. In: SILVA, Luiz H.; AZEVEDO, José C.; SANTOS, Edmilson S. Identidade social e a construção do conhecimento. Porto Alegre: Ed. SMED, 1997. p. 98-145.

STEINBERG, Shirley; KINCHELOE, Joe. Cultura infantil: a construção corporativa da infância. 2. ed. Rio de Janeiro: Civilização Brasileira, 2004.

TV PinGuim. 2012. Disponível em: <http://www.tvpinguim.com.br/ atvpinguim.html>. Acesso em: 26 jan. 2012.

WORTMANN, Maria Lúcia Castagna. Natureza e literatura infanto-juvenil. In: WORTMANN, Maria Lúcia Castagna et al. (Org.). Ensaios em Estudos Culturais, Educação e ciência. Porto Alegre: Editora da UFRGS, 2007. p. 187-204. 


\section{Educación Ambiental corpo- rativa para niños: análisis de La animación Peixonauta de Discovery Kids}

\section{Resumen}

A partir del análisis de la serie "Peixonauta", animación que integra la programación del Canal Discovery Kids, relacionado al grupo Discovery Channel, buscamos resaltar cómo algunos problemas ambientales se presentan a los nińos, así como discutir cómo se describen, en esta serie, algunas identidades conservacionistas. La animación "Peixonauta" pone de relieve cuestiones ambientales: introducción de especies exóticas y domésticas en la naturaleza y cómo esta práctica afecta el medio ambiente; la contaminación del agua, suelo y aire; y ciertos fenómenos naturales. Ubicado en la intersección de la educación, educación ambiental, estudios culturales y estudios de los medios de comunicación, este estudio cuestiona la forma con que este diseño enseña los problemas y, también, las acciones que deben considerarse en relación a los llamados entornos naturales. El corpus analítico consta de 30 episodios que destacan cuatro cuestiones ambientales: a) reciclaje de materiales; b) introducción de especies exóticas; c) contaminación; d) cambio climático y otros problemas asociados. Los resultados sugieren que el Discovery Kids practica un tipo de "educación ambiental corporativa" por introducir y utilizar temas "verdes" en su programación. En "Peixonauta",

\section{Corporate Environmental Education for children: analyzing the animated TV series Fishtronaut broadcast by Discovery Kids}

\begin{abstract}
By analysing the animated TV series Fishtronaut broadcast by the cable television channel Discovery Kids, which is associated to the Discovery Channel group, we point out how environmental issues are presented to children and how some preservationist identities are portrayed by this TV series. Fishtronaut emphasizes a number of environmental issues: the introduction of exotic and domestic species in nature, and how this affects the environment; water, soil and air pollution; and certain natural phenomena. Conducted at the intersection of the fields of education, environmental education, cultural studies and media studies, this study analyzes how this cartoon teaches which actions and problems should be considered in relation to the so-called natural environments. The analysis focused on 30 episodes that present four environmental themes: a) material recycling; b) introduction of exotic species; c) pollution; and d) climate change and associated problems. The results suggest that Discovery Kids practices a kind of "corporate environmental education" by introducing and drawing on "green" themes in its scheduling. This aim is clear in Fishtronaut. Some characters represent
\end{abstract}


se evidencia esta intención. Algunos caracteres representan sujetos conscientes del medio ambiente; otros enseñan lo que es ser "ambientalmente responsables". Hay también los que detienen el conocimiento legitimado. Además, la tecnología es puesta en el centro de atención como un medio para la solución segura y rápida de los problemas ambientales. Pero al mismo tiempo, haciendo la simplificación de la búsqueda de soluciones, la serie hace la naturalización / trivialización de los problemas ambientales, provocando su eliminación.

Palabras clave: Educación ambiental. Educación ambiental corporativa. Medios de comunicación y educación prescolar. subjects who are made environmentally aware; others teach "environmental responsibility". Others have legitimated knowledge. Moreover, technology is highlighted as a safe and fast way to solve environmental problems. But by simplifying solutions, the series tends to present environmental problems in a banal and naturalized manner, leading to their elimination.

Keywords: Environmental education. Corporate environmental education. Media and children's education.
Maria Lúcia Castagna Wortmann

E-mail:wortmann@terra.com.br

Daniela Ripoll

E-mail: daniela_ripoll@terra.com.br

Laís Possamai

E-mail: laispossamai@hotmail.com
Recebido em: 31/1/2012

Versão final recebida em: 18/7/2012

Aprovado em: 20/7/2012 